\title{
A INFLUÊNCIA MIDIÁTICA E DO SETOR PUBLICITÁRIO NO CONSUMO PRECOCE: UM OLHAR A PARTIR DA EDUCAÇÃO ECOLÓGICA PARA UM CONSUMO SUSTENTÁVEL.
}

\author{
THE MEDIA AND COMMERCIAL SECTOR INFLUENCE IN EARLY \\ CONSUMPTION: A VIEW FROM ECOLOGICAL EDUCATION FOR A \\ SUSTAINABLE CONSUMPTION.
}

\begin{abstract}
${ }^{1}$ Patrícia dos Reis
RESUMO

${ }^{2}$ Rafaela Bolson Dallafavera

O trabalho versa sobre os estímulos midiáticos e do setor publicitário no desenvolvimento de crianças e a adolescentes. Objetiva verificar se a exposição à publicidade do consumo influencia no comportamento dos infantes frente ao meio ambiente. Especificamente, descreve o meio ambiente como Direito Fundamental das presentes e futuras gerações sob a ótica da Doutrina da Proteção Integral, bem como a relação das mídias televisiva e online com o consumo precoce. Ainda, analisa o papel da educação ecológica na conscientização para um consumo sustentável. Para tanto, utiliza-se o método de abordagem dedutivo, método de procedimento monográfico e técnica de pesquisa bibliográfica.
\end{abstract}

Palavras-chave: Crianças e Adolescentes; Mídia; Proteção Integral; Educação Ecológica; Consumo Sustentável.

\begin{abstract}
The work deals with the media stimuli and the advertising industry in the development of children and adolescents. Aims to verify if the exposure to consumer advertising influences the behavior of infants towards the environment. Specifically, it describes the environment as a fundamental right of present and future generations from the perspective of the Integral Protection Doctrine, as well as the relationship of television and online media with early consumption. Also examines the role of environmental education in awareness of sustainable consumption. For this, it was used the deductive method of approach, monographic method of procedure and technical literature.
\end{abstract}

Keywords: Children and Adolescents; Media; Full Protection; Ecological Education; Sustainable Consumption.

\footnotetext{
${ }^{1}$ Mestranda em Direito pela Universidade Federal de Santa Maria - UFSM, Rio Grande do Sul (Brasil). Pesquisadora do Centro de Estudos e Pesquisa em Direito e Internet - Cepedi pela Universidade Federal de Santa Maria - UFSM, Rio Grande do Sul (Brasil). E-mail: patriciareista17@ yahoo.com.br

${ }^{2}$ Mestranda em Direito pela Universidade Federal de Santa Maria - UFSM, Rio Grande do Sul (Brasil). Pesquisadora do Núcleo de Direito Informacional - NUDI pela Universidade Federal de Santa Maria - UFSM, Rio Grande do Sul (Brasil). E-mail: rafaeladallafavera@hotmail.com
} 


\section{INTRODUÇÃO}

O presente trabalho propicia uma análise da influência das mídias televisiva e online e dos estímulos consumeristas frente ao comportamento dos infantes perante o meio ambiente.

Atualmente, se percebe forte ascensão nas mídias televisa e online, no que tange ao anúncio de produtos e serviços voltados para os infantes. Essa promoção visa fidelizar marcas e incentivar o consumo precoce, fato que tem tomado proporções preocupantes em diversas partes do mundo, inclusive no Brasil.

Partindo dessa premissa, entre as inúmeras influências midiáticas, há que se ressaltar a atual preocupação com o consumo precoce e a influência negativa que os estímulos consumeristas vêm gerando para o desenvolvimento dos infantes, especialmente quando se trata de proteção e consciência ambiental.

É nesse contexto que se justifica a presente pesquisa, ao passo que se percebe a necessidade de uma educação ecológica que possa promover percepções diferenciadas para crianças e adolescentes embasadas na proteção, respeito e solidariedade ao meio ambiente ecologicamente equilibrado como um direito de todos, inclusive das presentes e futuras gerações. Ademais que essa mesma educação possa promover ações para a conscientização de um consumo sustentável desde a primeira infância.

Para delinear o entendimento, se faz necessário pontuar algumas considerações partindo do reconhecimento do meio ambiente com direito fundamental e, sobretudo, da infância, protegida também sobre os ditames da Doutrina da Proteção Integral. Ainda, destacar as estratégias publicitárias desenvolvidas pelo setor publicitário e publicizadas pelas mídias televisiva e online no intuito de atrair os infantes para o consumo precoce. E, por fim, demostrar a importância de uma educação ecológica desde a primeira infância e sua relação com a conscientização para um consumo sustentável.

Para tanto, utiliza-se do método de abordagem dedutivo. Como método de abordagem foi empregado o monográfico, por tratar de um grupo específico de indivíduos, quais sejam, crianças e adolescentes. Logo, para a delimitação de tal procedimento, utilizar-se-á técnica de pesquisa bibliográfica fundamentada a partir da revisão, análise e interpretação da literatura com base em livros, artigos científicos, revistas eletrônicas e sites da Internet, a fim de colaborar para uma melhor demonstração do problema. 


\section{O DIREITO FUNDAMENTAL AO MEIO AMBIENTE PARA AS PRESENTES E}

FUTAS GERAÇÕES: uma análise sob a ótica da Doutrina da Proteção Integral.

Até o século XX, a legislação brasileira não havia se pronunciado sobre os direitos das crianças e adolescentes no país. Nesse sentido, importante ressaltar apontamentos históricos sobre a inserção desse direito no ordenamento jurídico brasileiro, bem como o reconhecimento do princípio da proteção integral.

Um dos primeiros passos percorridos na direção dos direitos dos infantoadolescentes brasileiros, se deu em meados de 1927 com a promulgação do primeiro Código de Menores, também conhecido como Código Mello Mattos. Tal regramento veio regulamentar principalmente as questões inerentes ao abandono e tutela, tendo em vista as diretrizes da situação irregular do "menor", a qual reconhecia crianças órfãs, mendigas e pobres ou quem cometera um ato infracional, como perigo a ordem pública. (LOPES e FERREIRA, 2013).

Sobre o tema, Veronese (1999 p. 27-28) explana:

O Código de Menores veio alterar e substituir concepções obsoletas como as de discernimento, culpabilidade, penalidade responsabilidade, pátrio poder, passando a assumir a assistência ao menor de idade, sob a perspectiva educacional. Abandonouse a postura anterior de reprimir e punir e passou-se a priorizar, como questão básica, o regenerar e educar. Desse modo, chegou-se à conclusão de que questões relativas à infância e à adolescência devem ser abordadas fora da perspectiva criminal, ou seja, fora do Código Penal.

Desse modo, a Constituição Federal da República de 1934 foi a primeira a se pronunciar em relação aos direitos das crianças brasileiras, com ênfase na proibição do trabalho infantil. Já a Constituição de 1937, outorgada pelo então Presidente Getúlio Vargas, se preocupou com a proteção dessas crianças, sobretudo as mais carentes. Além disso, estabeleceu que o Estado deveria promover assistência aos infantes, bem como assegurar seu desenvolvimento físico e moral. Nesse sentido, as famílias mais necessitadas contavam com um auxílio do Estado para subsistência e educação de seus filhos. Com a mesma acepção assistencial, a Constituição de 1969 se preocupou com a proteção da maternidade e da infância, bem como estipulou a obrigatoriedade das empresas em disponibilizar ensino primário gratuito para seus funcionários e filhos, incluindo nesse grupo, também os excepcionais. (VERONESE, 1999).

Com a promulgação da Constituição Federal da República de 1988, houve um considerável avanço no direito brasileiro, ao passo que se normatizaram os direitos e garantias 
fundamentais e se tratou de maneira específica dos direitos sociais, quais sejam, direito à educação, à saúde, ao trabalho, à segurança, à previdência social, à proteção aos desamparados e à proteção à maternidade e à infância ${ }^{3}$. Nessa seara, inovou em seu capítulo VII, dispondo dos direitos da família, crianças e adolescentes e dos idosos, registrando sob os ditames do art. 227, o marco inicial do princípio da proteção integral no direito brasileiro, intensificando a preocupação com o melhor interesse da infância. (PEREIRA JUNIOR, 2011).

Nesse passo, explana Custódio (2009, p. 26):

\begin{abstract}
A Constituição da República Federativa do Brasil e suas respectivas garantias democráticas constituíram a base fundamental do Direito da Criança e do Adolescente, inter-relacionando os princípios e diretrizes da teoria da proteção integral, e, por consequência, provocaram um reordenamento jurídico, político e institucional sobre todos planos, programas, projetos, ações e atitudes por parte do Estado, em estreita colaboração com a sociedade civil, nos quais os reflexos se (re) produzem sobre o contexto sócio-histórico brasileiro.
\end{abstract}

No que tange ao meio ambiente, a Constituição Federal da República de 1988, reconheceu o meio ambiente como sendo de interesse difuso, independentemente do seu grupo ou associação de pertencimento. Sobre os ditames do art. 225, caput, a Carta Magna brasileira trata do meio ambiente ecologicamente equilibrado e da sadia qualidade de vida para o uso de todos. Para tanto, além de ser reconhecido como um direito difuso é considerado igualmente um Direito Humano e Fundamental de terceira geração, ao passo que se trata de um direito transindividual. Para Almeida (2009), os direitos difusos e coletivos são enquadrados como direitos de terceira geração e nessa categoria incluem-se o Direito do Ambiente ou Direito Ambiental.

Tendo em vista a faixa etária abarcada pela presente pesquisa, cumpre destacar que o artigo ora citado deixa muito claro o dever do poder público e da coletividade em preservar o meio ambiente para as presentes e futuras gerações. (BRASIL, 2016).

Para Cappelletti (1996), o campo de atuação e interesse dos direitos difusos, não estão ligados aos fenômenos de massa como os interesses dos consumidores ou sobre assuntos ligados apenas a poluição, mas também em se tratando de meio ambiente, estão relacionados com interesses sociais de outras categorias, a exemplo das crianças.

Nesse sentido, no ano de 1990, com a promulgação da Lei 8.069/90 - Estatuto da Criança e do Adolescente, o legislador passou a priorizar o melhor interesse dos infantes, bem como instaurou um novo referencial político-jurídico ratificando os preceitos fundamentais e

\footnotetext{
${ }^{3}$ Reitera-se que a Emenda Constitucional no 20/2000 inseriu ainda no rol dos Direitos Sociais, o direito à moradia. Igualmente a Emenda Constitucional nº 64/2010 inseriu o direito à alimentação.
} 
reconhecendo crianças e adolescentes como sujeitos de direitos.

Além disso, passou a declarar os infantes como cidadãos e não mais como projeto de adultos, reconhecendo seus direitos em razão de indivíduos que estão crescendo, em condição peculiar.

Veronese (2003, p. 41) ratifica dizendo:

Dessa forma, percebe-se que o Estatuto e a CF vêem a criança e o Adolescente como cidadãos merecedores de direitos próprios e especiais em razão de sua condição específica de pessoas em desenvolvimento que estão a necessitar de uma proteção especializada, diferenciada e integra.

Desse modo, o texto constitucional do art. 227 , cumulado às normativas do art. $4^{\circ}$ do Estatuto da Criança e do Adolescente, passaram a estabelecer proteção prioritária para os infantes, sobre a perspectiva da proteção integral. Nesse passo, sempre que houver afronte aos interesses de tais indivíduos, a rede de proteção integral formada pela família, Estado e sociedade civil, deve estar apta para suprir quaisquer necessidades, sob a ótica da tutela coletiva.

Neste passo, registra-se o dever de respeito, bem como a necessidade de ações sustentáveis para, a partir da responsabilidade tríplice da rede de proteção integral, assegurar as presentes e futuras gerações um meio ambiente ecologicamente equilibrado. Ademais, o Estatuto da Criança e do Adolescente dispõe em seu art. $7^{\circ}$ que toda a criança e o adolescente têm direito a um desenvolvimento sadio e harmonioso, o qual cumpre destacar perpassar por aquele (BRASIL, 2016).

No entanto, sabe-se que hodiernamente o meio ambiente é visto como uma potencialidade econômica onde grandes empresas usam dos seus recursos naturais por meio de novas tecnologias para a produção desenfreada de seus produtos utilizando-se das mídias televisiva e online para publicizar seus produtos como necessários à qualidade de vida para a sociedade.

Pérez Luño (2012) trabalha muito bem essa questão ao tratar do meio ambiente como direito de terceira geração. $\mathrm{O}$ autor faz uma crítica aduzindo que a humanidade pode estar condenada a um suicídio coletivo, visto que as novas tecnologias contribuiram para o domínio e a exploração do meio ambiente de maneira ilimitada, considerando a natureza como a empresa em maior desenvolvimento, a qual o homem tem usado de maneira desenfreada para possibilitar uma melhor qualidade para a sua vida. 
Nesse sentido, Capra (1996), informa que estamos diante de problemas globais que estão danificando a biosfera e que, portanto, não podem ser entendidos de maneira isolada e interdependentes. Isso está relacionado à expansão, a busca incessante pelo lucro, a disseminação do consumo e pelo desejo de satisfazer necessidades insaciáveis. Para o autor a única solução viável, a partir de um ponto de vista sistêmico, seriam soluções sustentaveis, as quais a partir dos ensinamentos de Lester Brown se trata de uma sociedade onde as necessidades seriam satisfeitas, sem diminuir as perspectivas das gerações futuras, um grande desafio do nosso tempo. (BROUW, 1981 apud CAPRA, 1996, p. 14)

Logo, por vivermos em uma sociedade ficcionada pelos desejos e consequentemente pelo consumo, sem levar em consideração a proteção de um meio ambiente ecologicamente equilibrado para as futuras gerações, a próxima seção tratará de como esse consumo é disseminado, sobretudo pelas mídias tradicionais e online e quais as consequências para o desenvolvimento físico e mental dos infantes nessa perspectiva.

\section{A INFLUÊNCIA DAS MÍDIAS TELEVISIVA E ONLINE ENQUANTO FONTES DE ESTÍMULO AO CONSUMO INFANTIL.}

Tendo em vista os objetivos específicos da presente pesquisa, inerente destacar os ditames do Capítulo II do Estatuto da Criança e do Adolescente, o qual passou a tratar da Prevenção Especial. Dentre as medidas registram-se os arts. 76, 78 e 79, os quais visam chamar a atenção da rede de proteção integral, para as situações de vulnerabilidade a que os infantes estão expostos diariamente, como nos casos dos estímulos consumeristas, por meio da publicidade infantil (VERONESE e SILVEIRA, 2011).

Dessa forma, a publicidade conceituada por Kotler (2007, p. 587), como: “[...] qualquer forma, não pessoal, de apresentação ou promoção de ideias, bens ou serviços, paga por um patrocinador identificado", tornou-se uma das maiores fontes de estímulo ao consumo no Brasil e no mundo, acabando por atingir todas as faixas etárias, com crescente ascensão no mercado de produtos voltados ao público infantil.

Os profissionais da publicidade reconhecem as crianças de hoje como os consumidores adultos de amanhã e, portanto, investem bilhões todos os anos em estratégias expressivas de marketing visando prender a atenção dos infantes por meio das mais variadas mídias.

Partindo dessa premissa e, tendo em vista que a publicidade não existe de forma isolada, parte-se para uma sucinta demonstração dos principais meios utilizados pelo setor 
publicitário para exposição e divulgação dos seus produtos, quais sejam, mídia televisiva e Internet.

Desse modo, em consonância com a pesquisa Tic Domicílios de 2014, realizada pelo Centro de Estudos sobre as Tecnologias da Informação e Comunicação - CETIC, registra-se que a televisão atinge hoje cerca de $98 \%$ dos lares brasileiros (TIC DOMICÍLIOS, 2014). Em direção à faixa etária abarcada, pesquisas realizadas pelo Ibope e disponibilizadas pelo Projeto Criança e Consumo do Instituo Alana, afirmam que as crianças brasileiras passam em média 5:35min em frente à televisão, portanto suscetíveis ao poder persuasivo do setor publicitário. (PROJETO CRIANÇA E CONSUMO, 2016).

No que tange a programação televisiva hodierna, inerente ressaltar o surgimento de estratégias de marketing criativas e inovadoras focadas em prender a atenção dos telespectadores de forma imediata e por tempo determinado. Como exemplos a serem citados, registra-se as chamadas publicitárias invocadas por personagens fictícios vestidos ou criados a imagem de super-heróis, bem como a vinculação desses aos mais variados produtos no formato de brindes colecionáveis.

Essas inserções ocorrem diariamente durante os intervalos e nos espaços comerciais disponibilizados durante as programações, restando em fidelizar marcas a partir da promoção da fantasia e incentivo ao consumo precoce (STRASBURGER, 2011).

Nesse sentido, pesquisas realizadas pelo Instituto Alana (2009) afirmam:

\begin{abstract}
Até aproximadamente os oito anos de idade, elas misturam fantasia e realidade. Por exemplo, uma criança de mais ou menos quatro anos, quando está assistindo ao seu desenho preferido na TV e ocorre uma interrupção pelos intervalos comerciais, não entende que o programa acabou e iniciou-se um intervalo. E mesmo depois que consegue fazer tal distinção, é só aproximadamente aos 12 anos que tem condições de compreender o caráter persuasivo da publicidade.
\end{abstract}

Logo, percebe-se que a mídia televisiva reconhece os infantes como um mercado mundialmente rentável, não levando em consideração sua condição peculiar da infância e vulnerabilidade frente aos apelos publicitários. Preocupados com o aumento do ibope e maior visualização dos seus produtos focam em estratégias inovadoras para atrair o maior número de clientes potenciais e, consequentemente transmissores ativos das comunicações recebidas a seus núcleos sociais.

Já no que tange à Internet, pesquisas recentes sobre a expansão do seu uso nos domicílios brasileiros demonstram que em 2014 o percentual de famílias com computador e 
acesso a rede no país era de 50\% (TIC DOMICÍlIOS, 2014). Em se tratando de crianças e adolescentes, esse número impressiona, ao passo que, $77 \%$ dos infantes possuem acesso ao ciberespaço, sendo que $81 \%$ estão conectadas diariamente. Desse total, $79 \%$ apoderam-se de perfil próprio nas redes sociais e $61 \%$ já curtiram algum tipo de publicidade na rede, enquanto $30 \%$ tiveram acesso às estratégias publicitárias, por meio de sites com jogos online (TIC KIDS ONLINE BRASIL, 2014).

Nesta senda, dentre as mais variadas formas e estratégias publicitárias na Internet, como por exemplo, sites de destinação da empresa, banners, publicidade enviada por $e$-mail e uma estratégia recente chamada de unboxing ou unwarping (termo em inglês para o ato de desembalar produtos), importante destacar os jogos interativos denominados de advergames. É por meio desse último, que o setor publicitário visa atrair crianças e adolescentes para o consumo de produtos e serviços e consequentemente fidelizar sua marca por meio da experiência positiva que o jogo proporciona (SILVA, 2015).

No que diz respeito aos advergames, cumpre destacar que além de atrair os infantes para a fidelização de marcas de inúmeros seguimentos, expõe crianças e adolescentes aos mais variados riscos online, tendo em vista sua falta de discernimento para identificar o website oficial hospedeiro do jogo. A exemplo disso, cita-se o jogo fake ${ }^{4}$ do McDonald's, hospedado na página: www.mcvideogame.com (MC VIDEO GAME, 2016).

Em se tratando do objetivo principal dessa seção, qual seja demonstrar a influência das mídias televisiva e online e a sua relação com o consumo precoce no desenvolvimento da infância, o jogo fake relacionado à empresa McDonald's apesar de se tratar de uma paródia digital produzida pela empresa Molleindústria, é um dos primeiros jogos apresentados na busca online pelo advergame. Nesse sentido, cumpre destacar que, como dito anteriormente, os infantes não conseguem discernir entre a sátira e o real, levando o jogo a sério como se esse fosse o game oficial da empresa McDonald's, tendo em vista o logo da marca.

Ao iniciar o jogo é solicitado à criança que esta desmate o campo para criar o gado, o qual futuramente será abatido para a produção dos hambúrgueres vendidos pela lanchonete. Nesse momento é aberta uma caixa de texto informando o que segue:

Figura 1 - induz os infantes a não acreditar nas campanhas a favor do meio ambiente.

\footnotetext{
${ }^{4} \mathrm{O}$ jogo não foi criado pela empresa McDonald's e sim pela Molleindustria (http://www.molleindustria.org/), que é um movimento social italiano que cria jogos na forma de sátiras, como uma forma de crítica a modelos de negócios. Seu objetivo é apenas divertir e educar, não representa pessoas, atividades ou acontecimentos reais. Todos os cenários e situações são fruto da imaginação dos criadores. O conteúdo deste jogo não deve ser considerado real.
} 


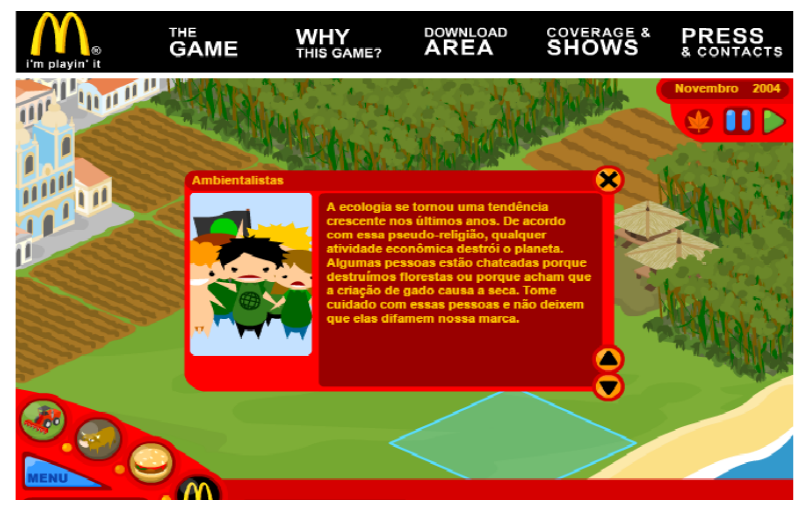

Fonte: www.mcvideogame.com

Em um segundo momento, é solicitado aos infantes que transportem o gado que está no pasto para a fábrica, onde esses serão abatidos para a produção dos hambúrgueres. Para um melhor entendimento da função que precisam desempenhar é disponibilizada a imagem de uma arma de fogo que fica sinalizada o tempo todo em cima do animal até que a criança ou o adolescente o abata. Quanto maior o número de gado abatido, maior a produção e consequentemente maior o consumo da lanchonete.

Figura 2 - incentiva insistentemente os infantes a matar o gado para a produção de hambúrgueres.

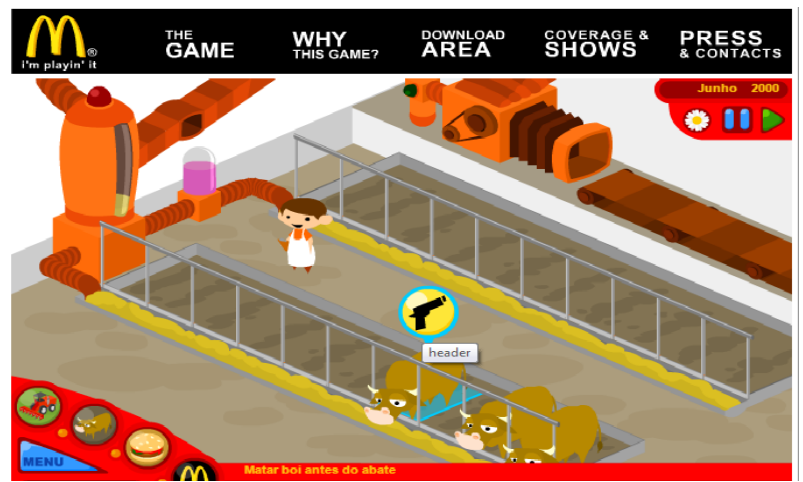

Fonte: www.mcvideogame.com

Cumpre destacar que o jogo só passa de fase mediante a realização de todos os comandos solicitados e que o comando mais requisitado é o abate do gado e o desmatamento da natureza para a sua criação. De tempos em tempos, enquanto os infantes estão passando de fases, como por exemplo, a venda de hambúrgueres, abre uma caixa de texto com a seguinte mensagem: "Não há hambúrgueres. Aumente o abate":

Figura 3 - incentivando o abate para o aumento da produção 


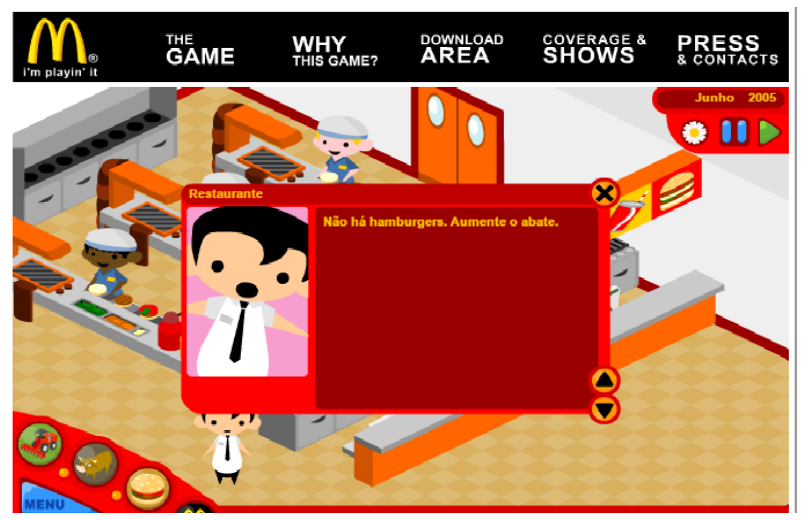

Fonte: www.mcvideogame.com

Superada a fase do desmatamento, do abate, da produção e da venda dos seus produtos, os infantoadolescentes são direcionados para o escritório da empresa, onde ficam todos os profissionais responsáveis desde o seu gerenciamento até o responsável pelas relações públicas da lanchonete.

Nesse ponto, quando a criança ou o adolescente clica em cima de cada funcionário são abertas caixas de textos informando como os infantes devem se comportar perante informações negativas sobre a empresa, sobretudo aquelas divulgadas pelos ativistas e pelas associações que lutam contra a obesidade infantil. Nesse sentido, são induzidos a creditar que os produtos vendidos pela lanchonete são saudáveis e possuem substâncias fundamentais para a saúde dos infantes. Ratificando, são as imagens que seguem:

Figura 4 - incentivando os infantes a se alimentar com seus produtos.

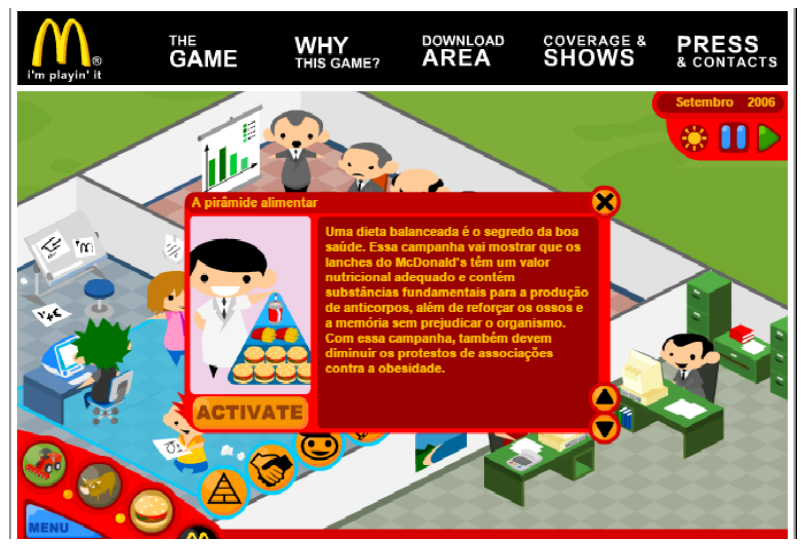

Fonte: www.mcvideogame.com

Ainda dentro do escritório, informam que as crianças são o seu público alvo, visto que estão livres de pensamentos críticos contra a marca e, portanto, tem uma maior aceitação dos seus produtos. Igualmente, sustentam a premissa de que as crianças convencem facilmente seus 
pais, que nunca irão reclamar em fornecer os lanches da empresa para seus filhos se solicitarem insistentemente por que estão com fome.

No mesmo sentido, buscam convencer os infantes que as estratégias de marketing e a publicidade infantil desenvolvida pela marca é um ótimo negócio. Ademais, que é por meio da publicidade que vincula seus produtos à brindes colecionáveis e a partir de suas mensagens subliminares que conseguem atrair seus clientes em potencial para a lanchonete e, portanto, essas tornam-se necessárias.

Figura 5 - informam que as crianças são o seu público alvo

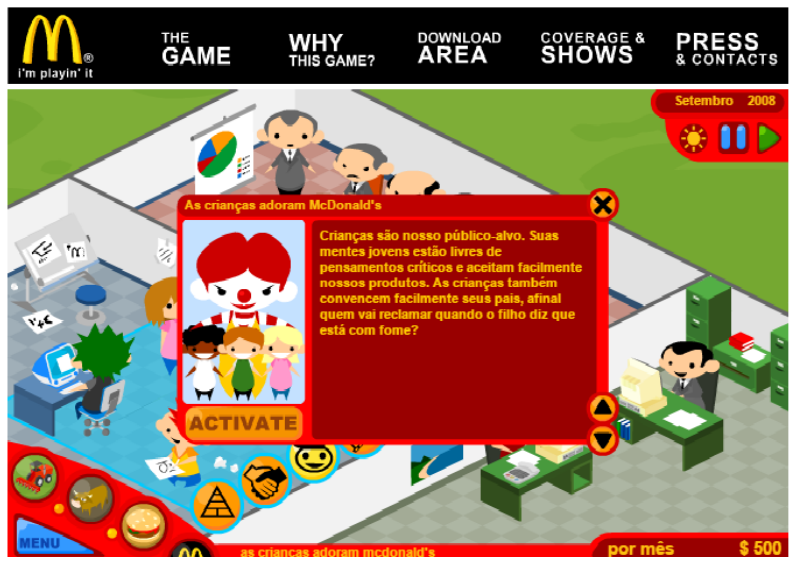

Fonte: www.mcvideogame.com

Figura 6 - incentivam as crianças e os adolescentes a acessarem informações publicitárias relativas a marca.

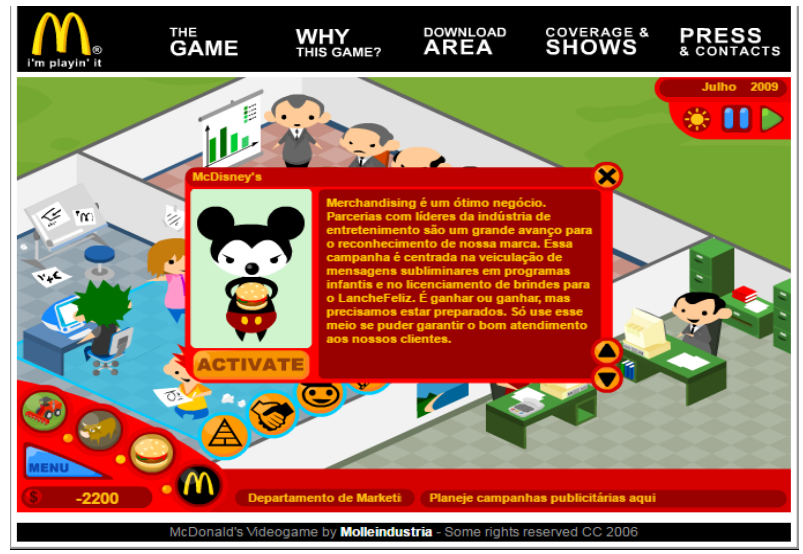

Fonte: www.mcvideogame.com

Quando os jogadores clicam em cima da mesa diretora da empresa, automaticamente é aberta uma caixa de texto onde aparece as discussões destes sobre todas as associações ativistas que lutam pela defesa do meio ambiente, relações de trabalho, combate a obesidade infantil e movimentos anti-globalização. As conclusões apresentadas para os infantes é que essas 
associações possuem "inveja" da empresa e, portanto, estão querendo boicotar a empresa. Solicitam às crianças que não deixem isso acontecer.

Figura 7 - diretoria da empresa informando que associações ativistas e protecionistas são invejosas.

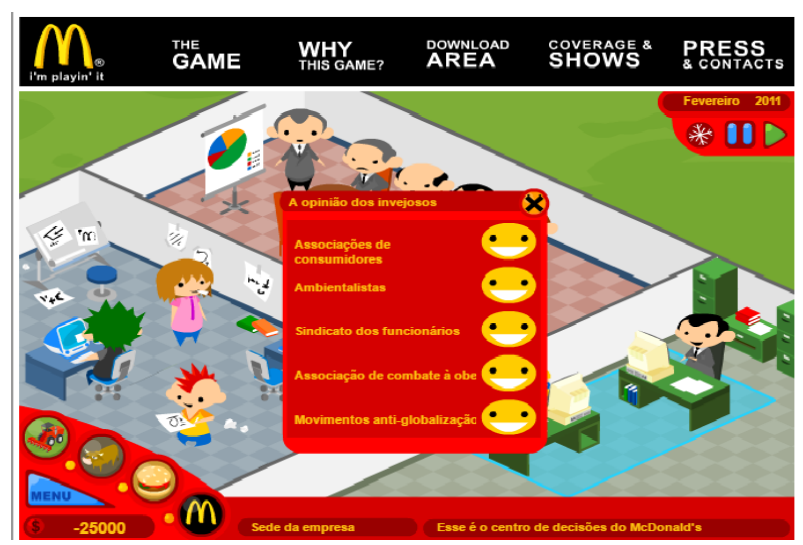

Fonte: www.mcvideogame.com

Por fim, o jogo informa que se a empresa pudesse evitar a derrubada das florestas, a poluição da água, ou a destruição da camada de ozônio o fariam. No entanto, isso acabaria por interferir na manutenção e no aumento de seus lucros. Para tanto, a criança é transportada para subornar um ambientalista, com vistas a garantir uma boa impressão do público e das ONGs.

Figura 8 - incentivando os infantes a subornar os ambientalistas para produzir e aumentar seus lucros.

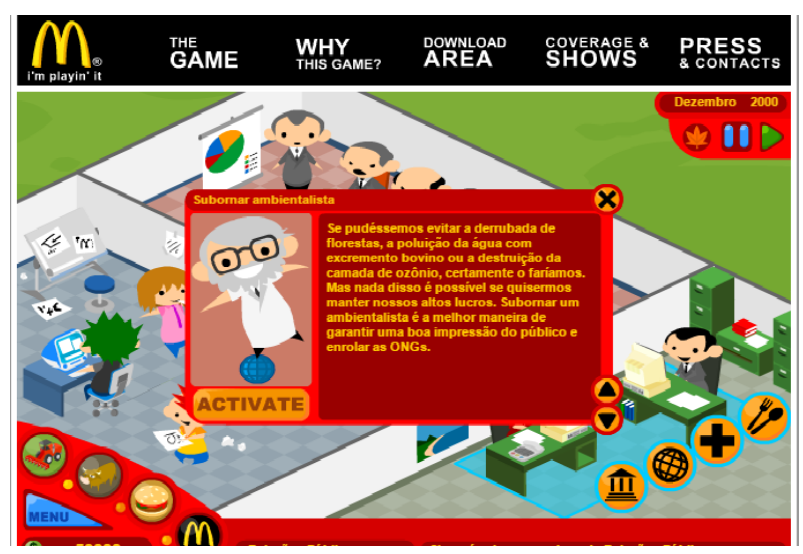

Fonte: www.mcvideogame.com

Assim, o jogo é finalizado e os infantes convidados a jogar novamente para tentar evoluir no gerenciamento da empresa, aumentar a produção de hambúrgueres e consequentemente, seus lucros. Desse modo, registra-se que em se tratando da faixa etária abarcada pela presente pesquisa e sua condição peculiar de infância, o jogo além de incentivar um comportamento negativo das crianças e dos adolescentes frente à preservação do meio 
ambiente, busca gerar um vício embasado na competição que certamente será disputado pelos amigos e colegas da escola.

Ademias, quanto mais o jogo é conhecido, mais é preciso jogar e evoluir na competição para que os infantes sejam aceitos e reconhecidos na roda de amigos como um jogador esperto e inteligente, independentemente da influência que esse jogo está a gerar na vida do seu meio. Nesse sentido, a disseminação de uma visão distorcida do meio ambiente como algo que não deve ser priorizado perante o lucro, também pode ser disseminada por meio do incentivo ao consumo precoce e passa, assim, a prejudicar gravemente o desenvolvimento físico e moral dos infantoadolescentes.

Nesse passo, percebe-se que os infantoadolescentes estão cada vez mais inseridos no contexto virtual e, portanto, expostos aos riscos dispostos na rede, de maneira especial a onipresença da publicidade infantil. Para compreender a emergência dessa nova realidade e sua inserção jurídica, bem como a interligação da mídia televisiva e online com a publicidade infantil, importante destacar que o setor publicitário estimula por meio de estratégias criativas e inovadoras, como os advergames, à aquisição do produto ou serviço enquanto definição de uma identidade pessoal.

Ratificando a informação, Feilitzen (2002) dispõe que os indivíduos constroem o significado dos conteúdos midiáticos, embasados pela orientação do ambiente onde vivem, bem como pela organização de sua vida sob os ditames considerados aceitos pelo seu núcleo social e, portanto, passam a consumir não mais pela satisfação de suas necessidades, mas sim na busca incessante de uma identidade considerada "aceita" pela percepção social.

Consequentemente, tal processo entendido como vitrine do consumo aumenta de maneira desordenada, considerando as crianças como um novo ramo de comércio, incentivando a mercantilização da infância e a mudança de pensamentos e valores, a exemplo da questão ambiental.

Ademais, percebe-se que a publicidade infantil desempenha um papel prejudicial à saúde dos infantes, visto que manobra, com a falta de discernimento dos sujeitos dessa faixa etária, propagando estímulos consumeristas, a fim de que estes se tornem consumidores em potencial (VERONESE e SILVEIRA, 2011).

Assim dispõe Vivarta (2013, p. 110):

O excessivo volume de propagandas direcionadas a esse grupo contribuiria, portanto, para uma comercialização da infância, fenômeno responsável por uma série de graves impactos no processo de desenvolvimento de meninos e meninas. Entre outros 
problemas, os especialistas apontam os transtornos alimentares, a erotização precoce, reações violentas e alcoolismo.

No contexto atual, as mídias televisiva e online estão focadas na exibição desenfreada de estratégias publicitárias atrativas capazes de lhe proporcionar retorno financeiro rápido, aumento do ibope e aquisição de clientes capazes de propagar os ideais da empresa. Esse processo vem tomando proporções preocupantes no Brasil e no mundo, ao passo que em pequenos lapsos temporais a publicidade voltada ao público infantil aumenta de maneira desordenada, considerando as crianças como um novo ramo de comércio.

Diante o exposto, restou provada a influência das mídias televisiva e online, bem como sua relação com o consumo infantil. Com vistas ao objetivo principal do presente trabalho, o próximo capítulo tratará da necessidade de uma educação ecológica na busca de uma conscientização por um consumo sustentável.

\section{A NECESSIDADE DE UMA EDUCAÇÃO ECOLÓGICA PARA UM CONSUMO SUSTENTÁVEL.}

A questão ambiental tem sido enfrentada como um problema que afeta o futuro da humanidade e deve mobilizar o Estado e a sociedade civil para uma mudança paradigmática nesse sentido. Desse modo, a esfera educativa tem assistido à formação de consensos sobre a educação ambiental, desenvolvidos em todos os níveis de ensino e de forma interdisciplinar no intuito de articular saberes, atitudes e valores de sensibilidade ambiental. Enquanto ação educativa a educação ambiental torna-se importante nos diálogos e nas reflexões sobre a crise ecológica (RICHTER, 2015).

No ordenamento brasileiro, a Constituição Federal da República de 1988 dispões em seus arts. 205 a 214 sobre a educação e o ensino propriamente dito. Cumpre destacar a diferença entre ambos, apesar de serem utilizados como sinônimos. A educação abarca um tema mais amplo do que o ensino. Para Bittar (2001, p. 15): envolve "todos os processos culturais, sociais, éticos, familiares, religiosos, ideológicos, políticos que se somam para a formação do indivíduo".

Ademais o art. 205 da Constituição Federal informa as finalidades da educação, quais sejam: desenvolver a integralidade do ser humano, seu preparo para a construção de uma cidadania ativa e, por fim, a qualificação profissional. Tais finalidades são ratificadas pelo 
Estatuto da Criança e do Adolescente em seus arts. 53 a 59. Logo, a educação é reconhecida como um direito subjetivo dos infantes e deve ser garantido pelo Estado.

Nesse sentido, Dallari (1999, p. 47) entende que a educação está ligada diretamente com o desenvolvimento individual da pessoa, ao passo que: “[...] ela torna as pessoas mais preparadas para a vida, para a convivência e para a reivindicação de seus direitos fundamentais". Para tanto, o direito à educação constitui-se em um direito social, sendo dever do Estado e da sociedade (por meio da participação), o desenvolvimento de políticas públicas de fomento à educação e ao ensino.

Para Maliska (2001) a educação é condição necessária ao desenvolvimento natural. Desse modo, não pode apenas tratar do ensino da leitura, compreensão de textos e cálculos, mas sim deve garantir o desenvolvimento de suas funções, bem como os dos valores morais e a convivência social.

Nesse norte, para Pires (2011, p. 65), os desafios da educação consistem: “[...] na busca e manutenção de estratégias para uma organização social de convivência mais justa e pacífica, ora transmitindo conhecimentos sobre a diversidade da espécie humana, ora conduzindo as pessoas a tomar consciência [...]".

Corroborando para a informação são as palavras de Gorczevski e Costa (2005, p. 127):

\begin{abstract}
A educação é um dos instrumentos mais importantes para a consolidação da cidadania. Evidencia-se a necessidade de redefinir-se o papel da educação como um direito fundamental e imprescindível para que a pessoa humana se realize e se torne capaz de construir vínculos fortes e estáveis entre os membros de sua comunidade, tendo por fundamentos a unidade social, a aceitação, a solidariedade e o senso de um destino comum, porque nada adiantaria ser cidadão sem a perspectiva ou possibilidade de pôr em prática essa prerrogativa: a de exercer a cidadania.
\end{abstract}

Com a mesma acepção, destaca-se a educação para os Direitos Humanos como forma de instauração de uma cultura preventiva. Santos (1995) aduz que essa educação consiste na prevenção das violações desses direitos. Registra ainda que essa fomenta condutas proativas e baseadas na tolerância, no respeito e na solidariedade, criando um ambiente de responsabilidade de todos na promoção e na efetivação dos referidos direitos (RICHTER, 2015).

Nesse sentido, é necessária uma nova concepção interdisciplinar preocupada com as relações dos seres humanos com o meio ambiente. O processo educativo precisa superar a noção de receptor do indivíduo e trabalhar em um contexto de construção para cidadãos participativos.

Para Veronese e Oliveira (2008, p. 37), a educação moderna deve ser entendida como um processo "[...] capaz de englobar a instrução, o desenvolvimento do sentimento e, ainda, um 
terceiro elemento: a cultura, que significa a transformação da natureza através da interferência humana". Logo, é preciso promover mudanças positivas e conscientes na mentalidade e nas ações dos indivíduos, comprometendo o sujeito consigo mesmo, com os outros e, sobretudo, com o meio ambiente onde vive.

No que diz respeito a faixa etária abarcada pela presente pesquisa, a educação, sobretudo a educação ecológica, deve assumir um poder transformador das novas gerações na promoção de um consumo sustentável, sendo que a base da sustentabilidade repousa na capacidade de uma nação promover o seu bem-estar e assegurar o bem-estar das presentes e futuras gerações.

Desse modo, garantir um meio ambiente ecologicamente equilibrado para as futuras gerações não depende somente da mudança de pensamento e comportamento da geração atual, mas no desenvolvimento de uma educação para o consumo, com vistas a um desenvolvimento sustentável.

Para Junges (2010, p. 58), desenvolvimento sustentável nada mais é do que: "aquele que satisfaz as necessidades das presentes gerações sem comprometer as das gerações futuras". Para tanto, no que tange ao consumo sustentável, o autor entende que os problemas ambientais não estão somente atrelados a produção industrial, mas especialmente nos níveis de consumo, onde sugere uma parceria entre os ambientalistas e os consumidores no intuito de juntar esforços para uma possível solução (JUNGES, 2010).

Nesse sentido, faz-se necessário que essa conscientização venha desde os primeiros anos de vida, a partir de uma educação ecológica embasada na coletividade e na preservação do meio ambiente como direito de todos. É necessário promover uma consciência solidária nos infantes de que, antes de serem apresentados para o mundo do consumo, esses precisam aprender os valores essenciais à sobrevivência humana fundamentados no respeito e responsabilidade com o meio que habitam. Igualmente, é preciso que eles entendam a sua relação de pertencimento com o meio.

Assim aduz: Gadotti (2005, p. 19):

\footnotetext{
A sensação de pertencimento ao universo não se inicia na idade adulta e nem por um ato de razão. Desde a infância, sentimo-nos ligados com algo que é muito maior do que nós. Desde crianças nos sentimos profundamente ligados ao universo e nos colocamos diante dele num misto de espanto e de respeito. E, durante toda vida, buscamos respostas ao que somos de onde viemos, para onde vamos, enfim, qual o sentido da nossa existência. É uma busca incessante e que jamais termina. A educação pode ter um papel nesse processo, se colocar questões filosóficas fundamentais, mas também se souber trabalhar ao lado do conhecimento, essa nossa capacidade de nos encantar com o universo.
} 
No entanto, esse processo de aprendizagem, que parece natural do ser, não ocorre dessa forma, pois o consumo é incentivado desde muito cedo, ou seja, antes de se formar cidadãos conscientes se treina para o consumo precoce.

A resposta para esse problema se encontra na educação para um consumo sustentável, visto que as crianças são a porta de entrada para uma nova aprendizagem, para uma mudança paradigmática no que tange ao desenvolvimento sustentável. Se aprenderem a consumir com consciência, crianças e adolescentes podem ser grandes transformadores sociais.

Essa mudança na educação, mesmo que muito tímida, já pode ser vista nas escolas, onde são tratadas de maneira pedagógica voltadas para a educação ambiental. No entanto, é preciso ir além e reforçar a ligação entre consumo e meio ambiente. É preciso reforçar o impacto das nossas escolhas no planeta e demostrar os danos que o atual modelo consumista já causou para que, em um processo evolutivo, possam mudar a consciência dos infantes sobre os seus hábitos consumeristas, que hoje são induzidos a conquistar um espaço no mundo do "ter".

Contudo, importante registrar que ninguém nasce consumista, são os hábitos e os estímulos desordenados ao consumo precoce que faz com que crianças e adolescentes criem o desejo por consumir, o que traz sérios problemas para a sustentabilidade. É difícil explicar para uma criança que, aquela embalagem de suco que hoje ela leva na lancheira da escola cumulada com todas as embalagens de sucos e bolachas trazidas pelos colegas, geram um impacto para o meio ambiente. Assim como, é difícil explicar para esses que muitas vezes aquele brinquedo que hoje eles consomem pode ter sido produzido em condições de desrespeito ao meio ambiente e a saúde dos trabalhadores.

Logo é preciso investir na educação ecológica, oportunizando que os infantes vivenciem todas as etapas do seu crescimento e que aos poucos possam aprender valores mais humanos e menos materialistas. No entanto, é preciso registrar que a educação ecológica não é responsabilidade somente da escola, e sim da tríplice rede de proteção integral formada pelo Estado, família e sociedade civil. Contudo, cabe ao Estado a promoção de políticas públicas que promovam uma educação, bem como uma conscientização sustentável e que os demais atores da rede de proteção integral, incluindo as empresas, sejam igualmente responsáveis e capazes de promover essas ações de forma harmônica, priorizando o desenvolvimento dos infantes e a preservação do meio ambiente para as presentes e futuras gerações 


\section{CONSIDERAÇÃOES FINAIS}

Os apontamentos iniciais prestaram-se a elencar breve apanhado histórico e evolutivo dos Direitos da Criança e do Adolescente no que tange ao Princípio da Proteção Integral, bem como o reconhecimento do meio ambiente como um Direito Fundamental. Nessa seara, destacou-se o reconhecimento dos infantoadolescentes como sujeitos de direitos e, portanto, merecedores de proteção em sua integralidade, responsabilizando a tríplice rede de proteção formada pela Família, Estado e Sociedade no tocante a proteção e prevenção para um meio ambiente ecologicamente equilibrado para as presentes e futuras gerações.

Ademais foi possível demonstrar a influência das mídias televisiva e online, cumuladas aos estímulos consumeristas, no que diz respeito à condição peculiar dos infantes para exibição desenfreada de anúncios publicitários criativos e inovadores com vistas a atrair o consumo infantil focados na satisfação de identidades pessoais e fidelização de suas marcas.

Outrossim, na segunda seção ficou provado que crianças e adolescentes carecem de atenção especial, tendo em vista se tratar de um grupo hipervulnerável em desenvolvimento físico, psíquico e moral, portanto incapazes de discernir sobre os estímulos publicitários, sobretudo tratando-se de influências negativas sobre o meio ambiente, conforme ficou provado pelo jogo fake do McDonlad's.

Na terceira e última seção foi apresentada uma breve contextualização do papel da educação ecológica no desenvolvimento de crianças e adolescentes, demonstrando sua real importância para um ensino responsável e solidário frente o meio ambiente que se habita. De maneira especial, para um repensar em uma educação conscientizadora, principalmente em se tratando de um educar para o consumo sustentável.

Logo, a presente pesquisa conclui pela necessidade de políticas públicas que possam investir em uma educação ecológica consciente dos problemas que atingem o meio ambiente hoje. Que a partir dessas, seja possível promover ações para o desenvolvimento sustentável, engajadas pelo respeito e reconhecimento do meio ambiente como direito de todos, sobretudo dos infantoadolescentes.

Ainda, que possam trabalhar desde a primeira infância sobre o impacto que decisões erradas podem gerar ao planeta, demostrando o dano que o modelo consumista já causou educando para um consumo sustentável. Para tanto, é preciso uma cooperação da tríplice rede de proteção para a implementação e realização dessas políticas capazes de promover o 
desenvolvimento saudável dos infantes, bem como o desenvolvimento sustentável e proteção do meio ambiente ecologicamente equilibrado para as presentes e futuras gerações.

\section{REFERÊNCIAS}

ALMEIDA, Paulo Santos de. Direito Ambiental Educacional: suas relações com os direitos da criança e do adolescente. São Paulo: Verbo Jurídico, 2009.

BITTAR, Eduardo C. B. Direito e Ensino Jurídico: legislação educacional. São Paulo: Atlas, 2001.

BRASIL. Constituição Federal da República. Disponível em:

http://www.planalto.gov.br/ccivil_03/constituicao/constituicao.htm. Acesso em: 02 de jul. 2016.

. Estatuto da Criança e do Adolescente. Disponível em: http://www.planalto.gov.br/ccivil_03/leis/18069.htm. Acesso em: 02 de jul. 2016.

BROWN, Lester R. Buüding a Sustainable Society. Norton, Nova York, 1981.

CAPPELlETTI, Mauro. GARTH, Bryant. Acesso à Justiça. Porto Alegre, Safe, 1998.

CAPRA, F. A teia da vida: uma nova concepção científica dos sistemas vivos. São Paulo: Cultrix, 1996.

CETIC. TIC DOMICÍLIOS 2014. Disponível em: http://cetic.br/pesquisa/domicilios/indicadores. Acesso em: 15 de mai. 2016.

TIC KIDS ONLINE BRASIL 2014. Disponível em:

http://nic.br/media/pdfs/apresentacoes/tic_kids_online_brasil_2014_hangout_imprensa.pdf. Acesso em 15 mai. 2016.

CUSTÓDIO, André Viana. Direito da Criança e do Adolescente. Núcleo de estudos em Estado, Política e Direito (NUPED) - Universidade do Extremo Sul Catarinense (UNESC). Santa Catarina, 2009.

DALLARI, Dalmo de Abreu. Direitos Humanos e cidadania. São Paulo: Moderna, 1999.

FEILITZEN, Cecília Von. Perspectivas sobre a criança e a mídia. Brasília: UNESCO/ Ministério da Justiça, 2002.

GADOTTI, Moacir. Pedagogia da Terra e Cultura de Sustentabilidade. Revista Lusófona de Educação, 2005, p. 5-19. 
GORCZEVSKI, Clovis; COSTA, Marli. Educação: a mais eficaz política pública de inclusão social. In: VIAL, S.R.M; LEAL, M. C. H.; REIS, J.R.; LEAL, R. G.. Anais do II Seminário Internacional sobre Demandas Sociais e Políticas Públicas na Sociedade Contemporânea. Porto Alegre: Evangraf, 2005.

INSTITUTO ALANA. Consumismo infantil na contramão da sustentabilidade. Disponível em: http://criancaeconsumo.org.br/wp-content/uploads/2014/05/ConsumismoInfantil.pdf. Acesso em: 15 jul. 2016.

KOTLER, Philip. Princípios de Marketing. São Paulo: Pearson Education, 2007.

JUNGES, José Roque. Bio (Ética) Ambiental. São Leopoldo, RS. Unisinos, 2010.

LOPES, Jacqueline Paulino; FERREIRA, Larissa Monforte. Breve Histórico das Crianças e dos Adolescentes e as Inovações do Estatuto da Criança e do Adolescente Lei 12.010/09. São Paulo: 2013.

LUÑO, Antonio Enrique Pérez. Los Derechos Humanos en la Sociedad Tecnológica: Editora Universitas. Madrid, 2012

MALISKA, Marcos Augusto. O direito à educação e a Constituição. Porto Alegre: Sergio Antonio Fabris Editor, 2001.

MCDONALD'S VÍDEO GAME. Jogo online. Disponível em: http://www.mcvideogame.com/index-por.html. Acesso em: 10 jul. 2016.

PEREIRA JÚNIOR, Antonio Jorge. Direitos da criança e do adolescente em face da TV. São Paulo: Saraiva, 2011.

PIRES, Nara Suzana Stainr. A educação como instrumento concretizador e produtor dos novos paradigmas da cidadania brasileira. Canoas: Editora Ulbra, 2011.

PROJETO CRIANÇA E CONSUMO. Tempo de crianças e adolescentes assistindo TV aumenta em 10 anos. Disponível em: http://criancaeconsumo.org.br/noticias/tempo-diariode-criancas-e-adolescentes-em-frente-a-tv-aumenta-em-10-anos/. Acesso em: 15 mai. 2016.

RICHTER, Daniela. O Direito da Criança e do Adolescente: o protagonismo e a sustentabilidade ambiental com direito das presentes e das futuras gerações. Tese de Doutoramento. Universidade Federal de Santa Catarina. Florianópolis, 2015.

SANTOS, Escobero Jorna. Presentácion. Educación en Derechos Humanos. Propuestas Didácticas. Madrid: Seccíon Española de Annistia Internacional, 1995.

SILVA, Rosane Leal da. O direito da criança e do adolescente desafiado pela era digital: repensando a prevenção especial em face de conteúdos prejudiciais e ilícitos difundidos na internet. In. VERONESE, Josiane Rose Petry; ROSSATO, Luciano Alves; LÉPORE, Paulo Eduardo. (Org) Estatuto da Criança e do Adolescente: 25 anos de desafios e conquistas. São Paulo: Saraiva, 2015, p. 277-296. 
STRASBURGER, Victor C. Crianças, adolescentes e a mídia. - 2. ed. - Porto Alegre: Penso, 2011.

VERONESE, Joseane Rose Petry. Os Direitos da Criança e do Adolescente. São Paulo: LTr, 1999.

Os direitos da criança e do adolescente: construindo o conceito de sujeito cidadão. IN: WOLKMER, Antônio Carlos, MORATO, José Rubens (orgs). Os direitos no Brasil: natureza e perspectivas: uma visão básica das novas conflituosidades jurídicas. São Paulo: Saraiva, 2003.

VERONESE; OLIVEIRA, Luciene de Cássia Policarpo. Educação versus Punição: a educação e o direito no universo da criança e do adolescente. Blumenau: Nova Letra, 2008.

, Josiane Rose Petry; SILVEIRA, Mayra. A criança, o adolescente e a televisão: proteção jurídica. In: COSTA, Marli Marlene Moraes da; PORTO, Rosane Terezinha Carvalho; REIS, Suzéte da Silva (Orgs.). Direito, Cidadania \& Políticas Públicas IV. Curitiba: Multidéia, 2011.

VIVARTA, Vett. Direitos da infância e direito à comunicação: fortalecendo convergências nos marcos legais e nas políticas públicas. Brasília, DF: ANDI, 2013. 